\title{
Féeries
}

Études sur le conte merveilleuX, XVII -XIX siècle

$11 \mid 2014$

L'illustration des contes

\section{Les images contées des colporteurs}

The Images Told by the Peddlers

\section{Catherine Velay-Vallantin}

\section{(2) OpenEdition}

Journals

Édition électronique

URL : http://journals.openedition.org/feeries/938

DOI : $10.4000 /$ feeries. 938

ISSN : 1957-7753

\section{Éditeur}

UGA Éditions/Université Grenoble Alpes

\section{Édition imprimée}

Date de publication : 19 décembre 2014

Pagination : 71-97

ISBN : 978-2-84310-281-3

ISSN : 1766-2842

\section{Référence électronique}

Catherine Velay-Vallantin, «Les images contées des colporteurs », Féeries [En ligne], 11 | 2014, mis en ligne le 19 décembre 2015, consulté le 30 octobre 2020. URL : http://journals.openedition.org/feeries/ 938 ; DOI : https://doi.org/10.4000/feeries.938

\section{(c) Féeries}




\title{
Catherine Velay-Vallantin \\ EHESS
}

\section{LES IMAGES CONTÉES DES COLPORTEURS}

\begin{abstract}
N IgII, dans la Revue d'Ethnographie et de Sociologie dont il est le directeur ${ }^{\mathrm{I}}$, Arnold van Gennep publie des Remarques sur l'imagerie populaire, inspirées par l'édition récente de l'Histoire de l'imagerie populaire flamande de E. van Heurck et J. Boekenoogen. Il y pose d'emblée cette question :
\end{abstract}

Étant donné que populaire se rapporte d'une part à l'acte de création, d'autre part au phénomène de la transmission, et enfin à celui de l'utilisation d'une forme prétendue collective d'activité, peut-on cependant, sous ce caractère à première vue collectif, discerner des tendances déterminées, et sont-elles réellement collectives, ou bien individuelles ${ }^{2}$ ?

Plus loin dans le texte, van Gennep constate combien le caractère "populaire» de la production de cette imagerie est dépendant de la gestion aussi bien économique qu'administrative des éditeurs, combien les procédés techniques interviennent aisément sur le sens des récits mis en images, combien les graveurs eux-mêmes, usant systématiquement du réemploi, se sont arrogés un droit d'intervention narratif sur les contes qu'ils illustrent. Avec une lucidité précoce face aux folkloristes de son temps, van Gennep révoque en doute les affirmations des collectionneurs et des bibliophiles qui voient en cette imagerie un jaillissement créatif, spontané et populaire, à l'authenticité indiscutable :

En somme, il faut reconnaître que plus on a de détails sur l'origine des bois pour imagerie populaire, plus on constate que ce n'est pas le peuple même qui est intervenu pour déterminer le mécanisme de la production, mais que ce mécanisme a été toujours sous la dépendance immédiate, disons même soumis au bon plaisir, des manies et des essais non coordonnés d'un très petit nombre d'éditeurs³.

I. A. van Gennep, «Remarques sur l'imagerie populaire», Revue d'Ethnographie et de Sociologie, Paris, Ernest Leroux, $\mathrm{n}^{\circ} \mathrm{I}-2$, I9II, t. II, p. 26-50.

2. Ibid., p. 26.

3. Ibid., p. 43. 
Ainsi, dès I9II, van Gennep œuvre en historien : alors que d'autres qualifient paresseusement ce fonds documentaire de "populaire», il fait preuve, quant à lui, d'une vision dialectique d'une étonnante modernité. Cette analyse présente l'avantage de poser de manière cruciale, et parfois cruelle, la question de l'instrumentalisation du "populaire" par les éditeurs qui le produisent, mais aussi par les lettrés, érudits et universitaires confondus, qui l'instrumentalisent.

Or, s'il révèle le caractère inventif des interventions éditoriales et dessine du même coup le graveur en auteur, van Gennep ne restitue pas pour autant l'immense et foisonnante circulation de thèmes, de motifs, de performances, écrites, lues, chantées, mises en scènes, et de rites, qui, s'entrelaçant sans fin, donne à l'image du conte une richesse qui, à défaut d'être "populaire» — mais faut-il qu'elle le soit? —, est assurément collective. Annie Renonciat a démontré combien, dès I790, la production de feuilles d'images obéit à deux systèmes narratifs ${ }^{4}$. D'un côté, les imagiers, pleinement investis dans leur effort pour transcrire le texte des conteurs lettrés, élaborent la grande série des représentations codifiées et prescrites par le récit antérieur; le conformisme de ces créations iconographiques, dominées par les habitudes d'imitation et de copie, révèle combien les contraintes habituelles aux arts graphiques prescrivent les données du "conte en image, produit stéréotypé, résumé, au sein d'une production standardisée, en quelques formules-clichés ${ }^{5}$ ». D’un autre côté, la concurrence est si vive entre les centres imagiers, français et européens, qu'il faut trouver de nouvelles formes de séduction : l'adoption de la lithographie, qui autorise toutes les libertés de trait et de mise en page, et le recours à de nouveaux artistes, formés à l'école de la caricature et de l'illustration, favorisent le renouvellement et la diversification des images consacrées aux contes. Ces représentations se libèrent alors de la tutelle de Perrault et de ses successeurs, "pour folâtrer, explorant tous leurs possibles, exerçant tous leurs pouvoirs, dans un irrespect délibéré du chef d'œuvre littéraire $^{6}{ }$. Je vais tenter, à travers deux exemples de contes mis en image, La Belle et la Bête et La Barbe Bleue, de restituer le bouillonnement créatif de ce creuset, où le conteur a certes toute sa place, mais ni plus ni moins qu'un autre narrateur, qu'il soit imagier, illustrateur, graveur ou éditeur. Dans le premier cas, l'image du livret de colportage sera le fil rouge de

4. A. Renonciat, «Et l'image, en fin de conte? Suites, fantaisies et variations sur les contes de Perrault dans l'imagerie", Romantisme, $\mathrm{n}^{\circ}$ 78, 1992, p. 103-I26.

5. Ibid., p. I03.

6. Ibid. 
cette démonstration; dans le deuxième, ce sera la planche d'Épinal qui restituera l'entrelacs des réinventions narratives.

\section{La Belle et la Bête : illusions optiques}

C'est en 1740 que Madame de Villeneuve fait paraître le conte La Belle et la Bête dans son recueil La Jeune Amériquaine et les Contes Marins, publié à La Haye. Cette version est à peu près conforme à celle, plus connue, de Madame Leprince de Beaumont, publiée en I757, tout au moins dans sa structure narrative essentielle. Les épisodes les plus spécifiques de la version de Madame de Villeneuve résident dans l'exploitation de thèmes fantasmagoriques, réitérés et abondamment développés tout au long du conte ${ }^{7}$.

Si la Belle est bien confrontée à une Bête, dont l'aspect l'effraie pour d'évidentes connotations sexuelles — « une horrible bête qui d'un air furieux lui mit sur le cou une espèce de trompe semblable à celle d'un éléphant» [à cet endroit du texte, p. 44, "lui» renvoie au père de la Belle] —, elle pourrait en réalité découvrir l'identité de son geôlier si elle était plus attentive à ses songes. En effet, la Belle rêve chaque nuit d'un bel inconnu qui n'est autre que la forme première de la Bête :

Un jeune homme beau comme on dépeint l'amour, d'une voix qui lui portait au cœur, lui dit: Ne crois pas, la Belle, être si malheureuse que tu le parais. C'est dans ces lieux que tu dois recevoir la récompense qu'on t’a refusée injustement partout ailleurs. Fais agir ta pénétration pour me démêler des apparences qui me déguisent. [...] Ensuite ce fantôme si charmant lui parut à ses genoux joindre aux plus flatteuses promesses les discours les plus tendres. (p. 69)

Or, ce rêve est mis en scène par une fée. La Bête en expliquera les mécanismes à la Belle, une fois intervenu l'heureux dénouement :

Elle me rendait invisible, et $\mathrm{j}$ 'avais la satisfaction de vous voir servir par des esprits qui l'étaient de même, ou qui se montraient à vous sous diverses formes d'animaux. Bien plus, la fée en dirigeant vos songes, vous faisait voir ma figure la nuit en idée, et le jour par mes portraits, et me faisait vous parler par la voie des songes, comme je pensais et comme je vous aurais parlé moi-même. Vous fûtes confusément mon secret, et mes espérances qu'elle vous invitait de remplir, et par le moyen d'un miroir constellé, j'étais témoin de vos conversations, et j'y voyais ou tout ce que vous imaginiez dire, ou tout ce que vous pensiez. (p. I62)

7. Madame de Villeneuve, "La Belle et la Bête», Le Cabinet des fées, ou Collection choisie des contes des fées, et autres contes merveilleux, ornés de figures, Amsterdam et Paris, I786, t. 26, p. 29-2I4. Les citations du conte de Madame de Villeneuve sont extraites de cette édition. 
Cette relation étrange ne se construit donc que par la grâce d'images, ou plus exactement par deux mondes d'images qui se croisent sans jamais se rencontrer. Et ce prince, qui n'est qu'une Bête ou une "idée», entoure la Belle d'illusions d'optique :

La Belle découvrit un théâtre des mieux illuminé. [...] À l'instant une douce symphonie, qui commença de se faire entendre, ne cessa que pour donner à d'autres acteurs que des comédiens singes et perroquets, la liberté de représenter une très belle tragédie, suivie d'une petite pièce qui, dans son genre, égalait la première. La Belle aimait les spectacles : c'était le seul plaisir qu'en quittant la ville elle eût regretté. Curieuse de voir de quelle étoffe était le tapis de la loge voisine de la sienne, elle en fut empêchée par une glace qui les séparait, ce qui lui fit connaître que ce qu’elle avait cru réel, n'était qu'un artifice, qui par le moyen de ce cristal, réfléchissait les objets et les lui envoyait de dessus le théâtre de la plus belle ville du monde. C'est le chef-d'œuvre de l'optique de faire réverbérer de si loin. (p. 8I-82)

Le château de la Bête recèle encore bien d'autres possibilités, telles que ces boîtes d'optique :

La Belle avait en ses fenêtres des sources intarissables de nouveaux amusements. Les trois autres lui donnaient, l'une le plaisir de la comédie italienne, l'autre celui de la vue des Tuileries où se rend tout ce que l'Europe a de personnes plus distinguées et des mieux faites dans les deux sexes. La dernière fenêtre n'était pas la moins agréable : elle lui fournissait un moyen sûr pour apprendre tout ce qui se faisait dans le monde. La scène était amusante et diversifiée de toutes sortes de façons. C'était quelquefois une fameuse ambassade qu'elle voyait, un mariage illustre ou quelques révolutions intéressantes. (p. 88)

\section{Le «tableau magique»}

Comme dans les versions les plus connues, la Belle souhaite s'enfuir du château. Mais ce n'est pas par l'entremise du miroir qu'elle s'inquiète de son père. En fait, elle est partagée entre les songes de la nuit et l'ennui qui la ronge tout au long de la journée, malgré le plaisir des spectacles qui lui sont offerts :

Quand la Belle fut éveillée, elle fit attention à ce songe qui commençait à lui paraître mystérieux. Mais il était encore une énigme pour elle. Le désir de revoir son père l'emportait pendant le jour sur les inquiétudes que lui causaient en dormant le monstre et l'inconnu. Ainsi ni tranquille la nuit, ni contente le jour, quoiqu'au milieu de la plus grande opulence, elle navait pour calmer ses ennuis que le plaisir des spectacles. (p. 92-93)

Plus que n'importe quel autre auteur, Madame de Villeneuve pose le problème de l'apparence, des effets d'optique, des plaisirs et des dangers 
de l'illusion. Le personnage de la Bête est tout autre, de ce fait, que ceux présentés par Madame Leprince de Beaumont et ses émules : non seulement la Bête n'a pas de nom, mais elle n'a pas vraiment de corps, ainsi que la "vérité» du rêve l'illustre. Et c'est bien par ce vide que la Belle se sent peu à peu menacée. Ce vide envahit l'espace auparavant si dense de la maison paternelle : cette maison originelle est détruite aux yeux du lecteur qui ne connaît plus que celle de la Bête, ce château riche en merveilles optiques ouvertes sur le monde entier ${ }^{8}$.

Or l'on s'ennuie dans ce château : l'ennui d'une Belle abandonnée à ellemême, mais guettée en permanence par une Bête invisible, coïncide avec les points culminants de l'angoisse, étapes qui jalonnent le récit, comme autant de points de repère. Cette Belle se sent à juste titre menacée dans son intégrité physique : toutes les enveloppes protectrices, le jardin, la maison, la chambre, le corps, l'esprit même, se révèlent insuffisamment protectrices. S'il est vrai que la notion d'étanchéité corporelle est déterminante pour une "bonne» constitution de l'image de soi, la Belle laissée dans cette situation de vulnérabilité est en vérité soumise à une opération de dépersonnalisation violente : au travers des rêves réitérés que la fée et la Bête lui imposent, l'héroïne doit s'avouer vaincue devant cet ennemi, cette «idée», ce "fantôme», capable de s'insinuer en elle-même, qui la vide de ses souvenirs, de sa famille, de son origine, de son passé, pour mieux se l'approprier. Cette intervention, véritablement physique, vise à une dissociation de la personnalité et s'effectue à l'aide de médiateurs fantasmagoriques et de prouesses techniques, où les boîtes d'optique jouent un rôle essentiel. Bien plus, le "miroir constellé», dont les versions ultérieures feront un autre usage, présente ici une fonction essentielle pour le voyeurisme de la Bête. Une fois de plus, l'identité de la Belle lui est dérobée par celui qui ne peut se définir que comme la non-identité, à la fois présent et absent, dedans et dehors. S'il est une violence faite à la Belle, c'est bien l'oubli de soi. Le thème du miroir exploité d'une autre façon par Madame Leprince de Beaumont accentue cet aspect du conte.

Nous connaissons bien le récit de Madame Leprince de Beaumont. Il a donné lieu à de nombreuses réappropriations, aussi bien à l'opéra

8. Sur ces merveilles optiques dans le conte de Madame de Villeneuve, voir A. Defrance, «La réfraction des sciences dans le conte de fées", Féeries, n 6, Le conte, les savoirs, 2009, p. 63-86; A. Gaillard, "Anamorphoses : les lieux d'illusion picturale dans la fiction (contes et romans) au XVIII ${ }^{\mathrm{e}}$ siècle", dans N. Ferrand (éd), Locus in Fabula, La topique de l'espace dans les fictions françaises d'Ancien Régime, Peeters, Louvain, 2004, p. 539-552.

9. D. Anzieu, «Le Moi-Peau», Nouvelle revue de psychanalyse, «Le Dehors et le Dedans», nº , printemps 1974 . 
que dans le colportage et la littérature enfantine, jusqu'aux derniers dessins animés de Walt Disney. Contrairement à Madame de Villeneuve, Madame Leprince de Beaumont choisit un autre usage optique, le miroir qui devient un "tableau vivant», pour mieux gérer le motif crucial du conte, celui où l'héroïne en proie à l'ennui demande à retourner chez son père. Le miroir lui offre alors l'opportunité de justifier son désir de fuite, puisqu'il lui montre son père mourant entouré de sa famille. Ce motif du miroir ne manque pas d'être exploité dans les mises en scène de l'opéra-comique de Marmontel et Grétry, Zémire et Azor, créé en I77I. Cette représentation lyrique du conte met en scène le fameux «tableau magique». Et cette scène bénéficie d'un tel succès qu'elle se trouve rapidement diffusée par une gravure de Pierre-Charles Ingouf, d'après une gouache de son frère François-Robert : cette estampe, "Zemire et Azor, dédié à Madame la Marquise de Montesse par son très humble et très obéissant serviteur Elluin", convoque aussi le nom du graveur François Rolland Elluin, notoirement connu pour ses illustrations d'ouvrages érotiques, sans que son intervention soit clairement avérée.

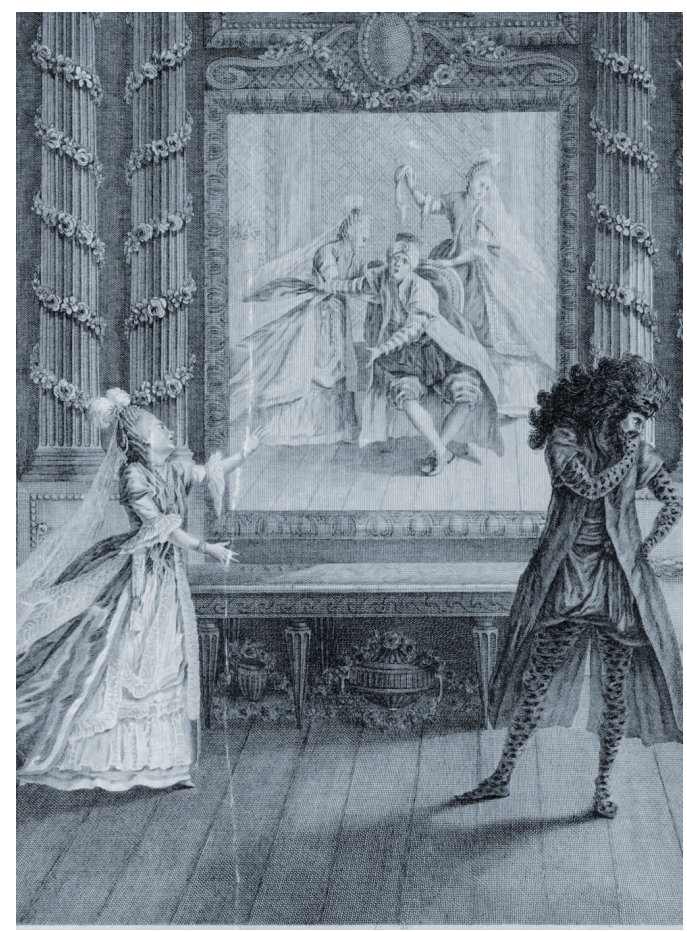

Fig. I. - Gravure de Zémire et Azor par Pierre-Charles Ingoulf. Bibliothèque nationale de France. 
Elle complète avantageusement les indications de Marmontel dans son livret, fort sommaires quant au décor : "Le théâtre représente un salon richement décoré à la manière orientale. Des vases de fleurs entre les croisées ${ }^{10}$."

La gravure montre Zémire et Azor de part et d'autre d'un grand tableau rectangulaire représentant trois personnages éplorés. Il s'agit en réalité d'un transparent. Derrière le rideau de gaze, fortement éclairée, la famille de Zémire chante un trio, accompagnée par un ensemble de vents placé dans la coulisse. Il existe aussi un dessin à la plume montrant la même scène lors d'une représentation à Versailles. Le décor, conçu par Mazières, est un peu différent. Les murs sont scandés d'imposantes colonnes ioniques; deux portes se trouvent dans des pans coupés; le tableau magique s'inscrit dans un arc en plein cintre. De plus, la place des acteurs se situe sur l'avantscène, près de la rampe, alors que la gravure de Ingouf les montre proches du mur du fond. Il est évident ici que Ingouf a effectué une transposition qui ne doit rien aux exigences de la représentation théâtrale, comme le montre le dessin à la plume, plus proche peut-être de la réalité de la mise en scène, tout au moins de la représentation versaillaise. L'artiste supplée les réalités scénographiques, l'esthétique de l'estampe ayant ses lois et ses usages propres. De ce fait, l'on ne peut savoir si Ingouf s'est inspiré de la création parisienne et il est difficile d'en conclure que la reprise versaillaise fut différente quant aux décors et à la mise en scène : il va de soi que, de ce point de vue, cette gravure ne peut présenter de véritable intérêt historiographique et ne nous donne que des indications imparfaites et tronquées sur la mise en scène, les costumes et les décors. En revanche, son statut de document historique lui vient d'un motif graphique qui ne peut laisser indifférent : Ingouf marque très nettement la continuité des boiseries, ininterrompues du parquet au miroir, comme s'il s'agissait d'un miroir sans tain. Aussi bien, la Belle ne peut-elle s'y réfléchir. La place des personnages, placés face au «tableau magique» et ne s'y réfléchissant pourtant pas, la continuité des rainures dans le miroir, autant de motifs qui dénotent le choix de production d'Ingouf, celui de l'unité graphique et textuelle, à la différence du dessin à la plume qui n'est peut-être rien d'autre que la représentation de la représentation versaillaise. Cette configuration du miroir et des personnages est devenue, de toute évidence, le problème essentiel auquel les éditeurs se sont heurtés : ce miroir qui ne réfléchit rien, qui est le vide même, comment le représenter?

Io. Cité par R. Legrand, «La scène et le public de l'Opéra-Comique de 1762 à I789", dans P. Vendrix (dir.), L'opéra-comique en France au XVIII' siècle, Liège, Mardaga, I992, p. I78-I86. Voir les reproductions de la gravure d'Ingouf et du dessin anonyme de la représentation versaillaise, p. I77 et 222. 


\section{Comment colporter un spectacle optique?}

Et de fait, les éditeurs ont majoritairement pris parti pour la non-représentation. Le motif du père mourant vu dans le miroir magique, pourtant nécessaire à la bonne compréhension du conte, est absent de toutes les planches d'images au XIX ${ }^{e}$ siècle : Charles Pellerin à Épinal édite La Belle et la Bête, en l'associant par deux fois à deux autres contes, Le Chat Botté et Les Trois Souhaits, sans qu'une seule fois ne soit illustrée la scène du miroir. Cette absence est tout aussi criante chez Marcel Vagné, éditeur de l'Imagerie de Pont-à-Mousson, et chez Olivier Pinot, Imprimeur-Lithographe de la Nouvelle Imagerie d'Épinal. Si le colportage de la seconde moitié du XIX ${ }^{\mathrm{e}}$ siècle refuse clairement le thème du reflet, la Bibliothèque bleue des XVIII ${ }^{e}$ et $\mathrm{XIX}^{\mathrm{e}}$ siècles montre tout autant de réticence : le seul éditeur débusqué à ce jour qui se risque à cette représentation est $\mathrm{F}$. Deckherr de Montbéliard. Le recueil des Contes plaisants de la Belle et la Bête, Le Prince Charmant et Les Trois Souhaits. Par M. Perrault, qui paraît à Montbéliard en I822, est distribué par Madame Garnier de Troyes, rue du Temple ${ }^{\text {II }}$.

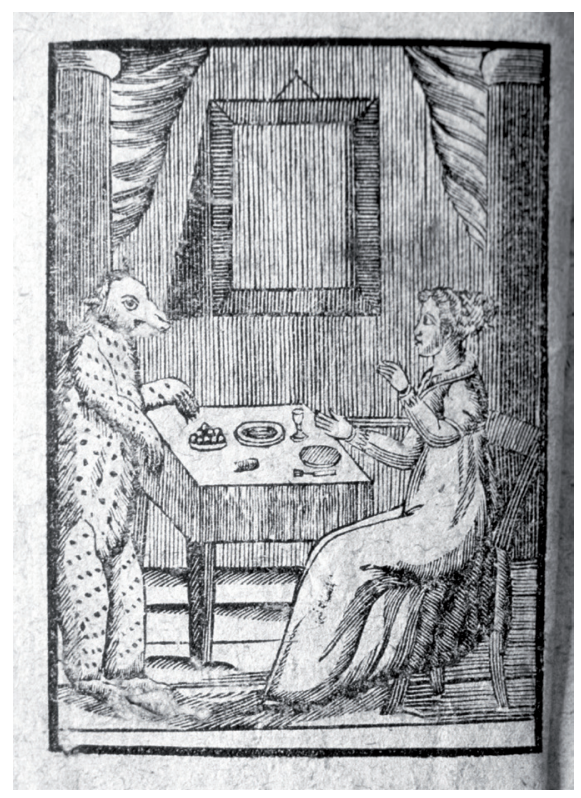

Fig. 2. - Frontispice des Contes plaisants de la Belle et la Bête, Le Prince Charmant et Les Trois Souhaits (1822).

Collection privée.

II. Voir la description de cette édition dans A. Morin, Catalogue descriptif de la Bibliothèque bleue de Troyes (Almanachs exclus), Genève, Droz, 1974, n ${ }^{\circ}$ 184, p. 87. 
Le frontispice de cette édition, en regard de la première page du texte, montre la Belle attablée avec la Bête; un miroir est accroché au mur. L’ombre projetée de cette glace est étonnamment décalée. De plus, selon le même procédé utilisé par Ingouf, les rainures murales se prolongent au cœur du miroir. Si cette illustration doit peut-être son origine à Ingouf, dont la gravure a été largement diffusée, il est possible aussi que le graveur de F. Deckherr se soit associé à l'interprétation de l'éditeur anglais Lumsden $\&$ Son qui publie vers I8Is à Glasgow un chapbook (livret de colportage), Beauty and the Beast. I A Tale.

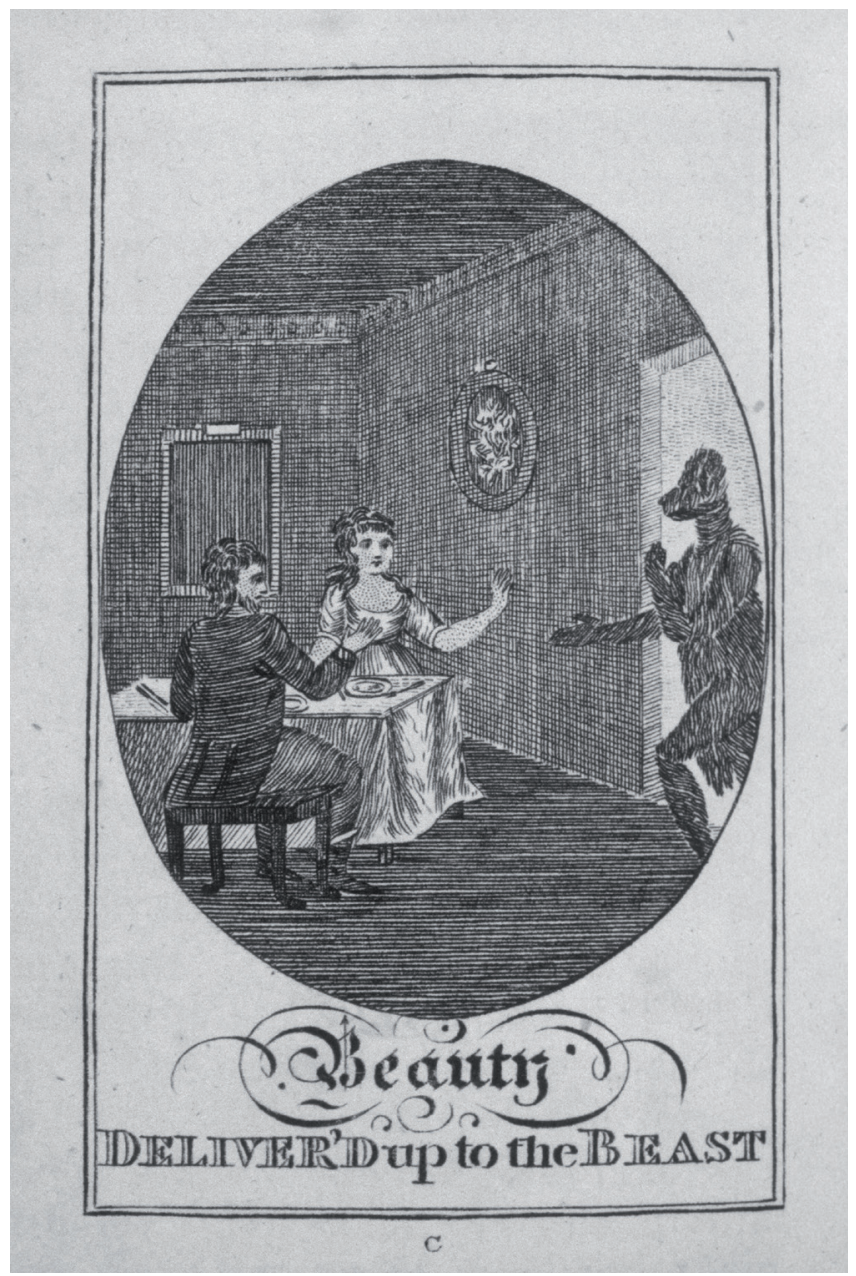

Fig. 3. - Gravure du Beauty and the Beast / A Tale (1815). Collection privée. 


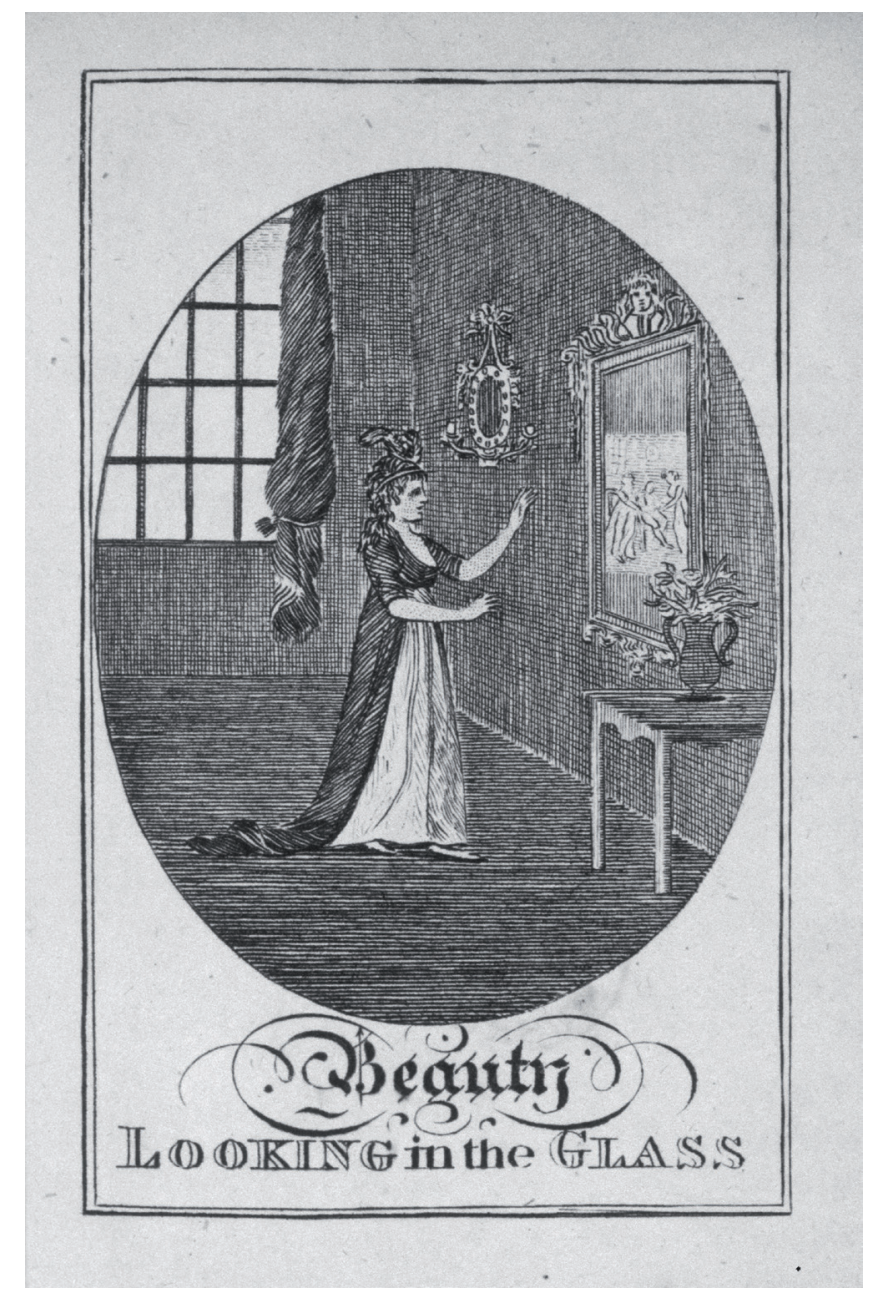

Fig. 4. - Gravure du Beauty and the Beast / A Tale (I8I5).

Collection privée.

Assorti de six gravures, ce chapbook met en scène l'épisode du miroir : la glace ne réfléchit pas la Belle et semble bien, lui aussi, s'intégrer à l'environnement mural. La scène du père malade entouré de ses filles est pourtant bel et bien projetée. Mais un examen attentif de la gravure rend compte d'une étrangeté optique : cette vision est destinée au lecteur. Le personnage de la Belle, placé de côté, ne peut l'entrevoir. Le miroir fonctionne alors comme un écran sur lequel serait projetée, par derrière, une image de format rectangulaire, qui pourrait passer pour une lithographie à transparences : éclairées par derrière, ces lithographies, imprimées recto-verso, 
laissent apparaître une nouvelle image en surimpression de la première; elles trouvent leur place dans les boîtes d'optique et dioramiques qui font fureur au XIX ${ }^{\mathrm{e}}$ siècle, mais aussi dans les boîtes d'optique "théâtrales» du $\mathrm{XVIII}^{\mathrm{e}}$ siècle qui nécessitent de disposer, à l'intérieur d'une caisse rectangulaire en bois, une longue série de décors et de personnages en papier découpér $^{12}$. Le chapbook nous offre, à n'en pas douter, un spectacle optique : et même si l'on peut également envisager que le halo lumineux entourant la vision du père malade relève de l' "aberration chromatique" propre aux lanternes magiques du XVIII ${ }^{\mathrm{e}}$ siècle, le chapbook nous impose ici un seul et unique système de compréhension du conte, celui qui lie optique et fantastique, optique et folklore.

\section{Une littérature de science-fiction}

Le thème du reflet qui se trouve au centre du conte fait donc l'objet de l'intrusion de l'optique dans la structure narrative : l'accent est mis sur la perte dont la vision dans le miroir constitue un médiateur proprement fantastique. Un égarement fondamental est alors théâtralisé : c'est une angoisse dépourvue de qualifications morales qui génère les décisions des personnages. Les auteurs, en particulier Madame de Villeneuve, construisent de ce fait leur récit selon une structure «en miroir", qui n'est pas seulement une prouesse technique. Le producteur lettré du conte met en scène la perte même, celle vécue par la Bête avant sa rencontre avec la Belle, celle vécue par la Belle une fois la Bête rencontrée, et alors à tout jamais liée à l'invisibilité, à l'absence de passé, à l'oubli de soi, à l'absence d'identité. Une des caractéristiques les plus sensibles de ces contes lettrés consiste pour leurs auteurs à constituer une littérature fantastique qui aurait aussi des origines folkloriques : l'appropriation des phénomènes et des effets d'optique se révèle dans le thème de la mise en présence de deux images se mettant réciproquement en question, d'où il découle une vue relativiste du monde.

Il est aussi naturel que l'invention ou la popularisation de nouveaux dispositifs permettant d'affiner ou de modifier la vision de l'œil réel aient influé sur les représentations que les producteurs et les récepteurs de récits folkloriques se sont faites alors du fonctionnement de cet œil métaphorique. C'est ainsi que l'invention de nouvelles techniques permet non seu-

I2. L. Mannoni, Trois siècles de cinéma. De la lanterne magique au Cinématographe, Collections de la cinémathèque française, Éd. Réunion des musées nationaux, Paris, 1995, p. 49-54. 
lement de qualifier de nouvelles modalités de l'imaginaire narratif mais aussi, dans une certaine mesure, de les promouvoir. L’optique permet aux phénomènes mentaux mis en scène dans le conte de se matérialiser sous forme de scènes, de figures ou de tableaux que l'image et le vocabulaire ont enregistrés ${ }^{13}$. Il n'est donc pas étonnant que les éditeurs se soient, dans une certaine mesure, affiliés aux appropriations mondaines et lettrées. À leur tour, ils pouvaient matérialiser sur le plan graphique ce que l'auteur fixait par son registre sémantique et son élaboration narrative. Que signifie alors la rencontre entre le fantastique et l'optique, entre le folklore et l'optique? Il serait erroné d'adopter une attitude positiviste face aux gravures des livrets de la Bibliothèque bleue et des chapbooks: à la mesure de celle d'Ingouf, ces gravures ne rendent compte que très imparfaitement des prouesses techniques du moment. Ce n'est pas leur but, ni leur fonction. En revanche, des images aux effets optiques déroutants apportent un surcroît de signification au conte. Mieux : elles dévoilent les mondes parallèles, les différents "tableaux vivants" d'un folklore multiple dans ses compréhensions. Comment ne pas prendre conscience alors que le conte se présente sous l'espèce d'une superposition ou d'une disjonction d'espaces, et qu'il se réinvente, d'éditeurs en lecteurs, par la grâce des duplications ou de symétries des personnages, des anticipations ou des chevauchements spatio-temporels? Et si le conte de La Belle et la Bête restitue toutes les fantasmagories proposées par Robertson dans ses spectacles de lanterne magique, si le merveilleux scientifique qui le signifie est redevable aux inventions $\mathrm{du}$ "fantascope», c'est que, à l'aune de tous les récits folkloriques, il ne rend pas compte d'une réalité cohérente et compacte. Mais il n'y a pas que cela : apparaît ici très clairement le rôle de suppléance que le spectacle optique a joué chez les publics de Robertson comme chez les lecteurs de Deckherr en France et de Lumsden \& Son en Angleterre, autant d'éditeurs qui se font ici les relais des producteurs mondains des contes. En effet, c'est au moment où la question de la croyance est le plus vivement débattue dans les milieux lettrés que l'on choisit d'exploiter l'image optique dans la littérature et le théâtre. L'on joue sur l'installation d'une incertitude perceptive, faite à la fois d'adhésion et de dénégation : le conte peut alors intégrer les effets optiques à sa thématique ${ }^{\mathrm{I} 4}$.

I3. J. Starobinski, La Relation publique, Paris, Gallimard, I970 («L'Empire de l’imaginaire, A : Jalons pour une histoire du concept d'imagination») p. 173-195.

I4. M. Milner, La Fantasmagorie. Essai sur l'optique fantastique, Paris, PUF, 1982, p. 9-38. 


\section{Le «merveilleux fin-de-siècle»}

Dans ses travaux fondateurs sur le "merveilleux fin-de-siècle ${ }^{15}$ ", Jean de Palacio démontre brillamment que la perversion et la subversion du merveilleux s'exhibent avant tout comme une pratique de composition et d'écriture. Dans la mesure où un conte se construit selon des lois narratives bien définies, pervertir un conte, c'est attenter à son sens, à son esprit et à sa lettre. C'est écrire à rebours d'une tradition bien attestée, représentée ici par les Contes de Perrault. C'est faire violence aux attendus du conte. C'est aussi privilégier la partie aux dépens du tout, être infidèle aux proportions, grossir le détail minuscule, dénaturer les mobiles, brouiller les rôles, abâtardir le langage. C'est enfin inverser le beau et le laid, le bien et le mal, de façon durable et permanente. Tous les repères habituels au lecteur de contes sont bouleversés. Parmi d'autres, il existe une manière de subvertir le conte : c'est d'en inventer la suite. Cette tentation a toujours existé et la Décadence ne l'invente pas. Mais il convient de distinguer entre le désir de continuer une œuvre laissée inachevée par la mort de son auteur et celui de rouvrir indûment un système clos ou considéré comme tel. La seconde moitié du XIx ${ }^{\mathrm{e}}$ siècle a multiplié cette pratique. Or, par définition, la suite relève de l'imitatio et non de l'inventio. Elle est de l'ordre de la répétition et du plagiat, mais c'est un plagiat proclamé qui ne cherche pas à cacher ses origines. Dans la mesure où le continuateur s'oppose au créateur, il est un homme de Décadence. La suite fait violence à la clôture, ouvre une brèche dans un espace textuel réputé parfait, affuble une œuvre d'attendus, un héros d'une postérité qui ne peut que les travestir. L'exploitation à outrance des archétypes ne saurait alors aboutir qu’à des stéréotypes.

Par contrecoup, avec effet rétroactif, le texte fondateur se trouve atteint par cette pratique. S'il est gros de toutes les dérives et de tous les ressassements qu'on lui impose, c'est qu'il était lui-même impur et portait les germes de sa propre décadence. La densité de l'original risque de pâtir du travail parasite des continuateurs. Il apparaît ainsi anachronique ou périmé dans les remises successives au goût du jour. «Le Code Napoléon est appliqué aux Fées et aux Génies pour la première fois ", proclame Léo Lespès, l'auteur des Contes de Perrault continués par Timothée Trimm ${ }^{16}$.

I5. J. de Palacio, Les perversions du merveilleux, Paris, Séguier, 1993; Figures et formes de la décadence, Paris, Séguier, I994. Voir N. Chatelain, "Lorsque le titre se fait épitaphe : chronique de la mort annoncée du conte-de-fée fin-de-siècle», Fabula $L H T, \mathrm{n}^{\circ}$ 6, Tombeaux de la littérature, mai 2009.

I6. L. Lespès, Les Contes de Perrault continués par Thimothée Trimm, illustrés par Henry de Montaut, Paris, Librairie du Petit Journal, I865, Lettre-préface à Henri de Montand du Io décembre I864, p. I. 
Face à la naïveté du texte initial, le continuateur se donne pour un esprit éclairé, un exégète lucide, un moderne. Il écrit «afin que l'esprit des petits lecteurs ne soit pas égaré par la jurisprudence de Mélusine et de l'enchanteur Merlin, tombée depuis longtemps en désuétude ${ }^{17}$ ». Descendant le cours du temps, la suite entraîne un changement de registre qui est l'essence même de la perversion, puisqu'il revient à dénaturer les intentions du texte fondateur en lui prêtant des mobiles qu'il n'avait jamais eus et un langage qu'il ne pouvait tenir, et tout en feignant de conserver des conventions anciennes désormais en porte-à-faux. Par sa nature même, le merveilleux a tout à perdre de ces remaniements. Il se voit, par une confusion volontaire, assimilé à la littérature «sérieuse", ce qui permet ainsi à Lespès de justifier son Perrault renouvelé : «On a bien fait des suites à l'Iliade, aux œuvres de Balzac, aux tragédies inachevées de Racine, les nains ne sont pas plus à l'abri de ce danger que les grands hommes ${ }^{18}$.»

C'est avant tout la notion d'épilogue que les écrivains de la Décadence ont remis en question. Ils ont moqué chez Perrault le recours optimiste, en épilogue, aux grandes consolations morales. Mais il n'y a pas que cela : ces entreprises de réélaboration manifestent une volonté d'abolir un préjugé : l'origine même des contes, cette oralité vive et inventive d'un conteur dont la performance, publique, serait avant tout un exercice d'autorité. Ces suites, ces «mécomptes de fées ${ }^{19}$ », témoignent en fait d'une révolte et d'un coup de force littéraires : le conte est remanié de façon à devenir un genre lettré parmi d'autres et il convient alors que l'auteur — un auteur parmi d'autres auteurs de nouvelles ou de romans — cherche à piquer la curiosité anxieuse du lecteur incertain de ce qui est arrive comme de la manière de l'interpréter. Comme dans un roman, l'auteur de conte de la Décadence entraîne le lecteur dans la découverte progressive d'un caractère et d'une situation. Comme dans un roman, il dispense juste ce qu'il faut d'informations pour relancer l'intérêt du lecteur, pas assez cependant pour diminuer sa perplexité. Le conteur ne cache rien à son auditoire et rien n'assure vraiment qu'il ne s'agisse pas là d'une stratégie destinée à camoufler le pouvoir de sa parole en action. L'auteur de la Décadence, en revanche, évite au lecteur de précipiter ses interprétations et, de ce fait, l'associe au travail de l'œuvre. Et si nous nous trouvions devant une entreprise de démocratisation du conte? Face à ce coup de force lettré, quelle fut la réponse des imagiers?

17. Ibid.

I8. Ibid.

19. Willy, "Mécomptes de fées», Une passade, Paris, Flammarion, I894. 


\section{Histoire de Madame Barbe-Bleue}

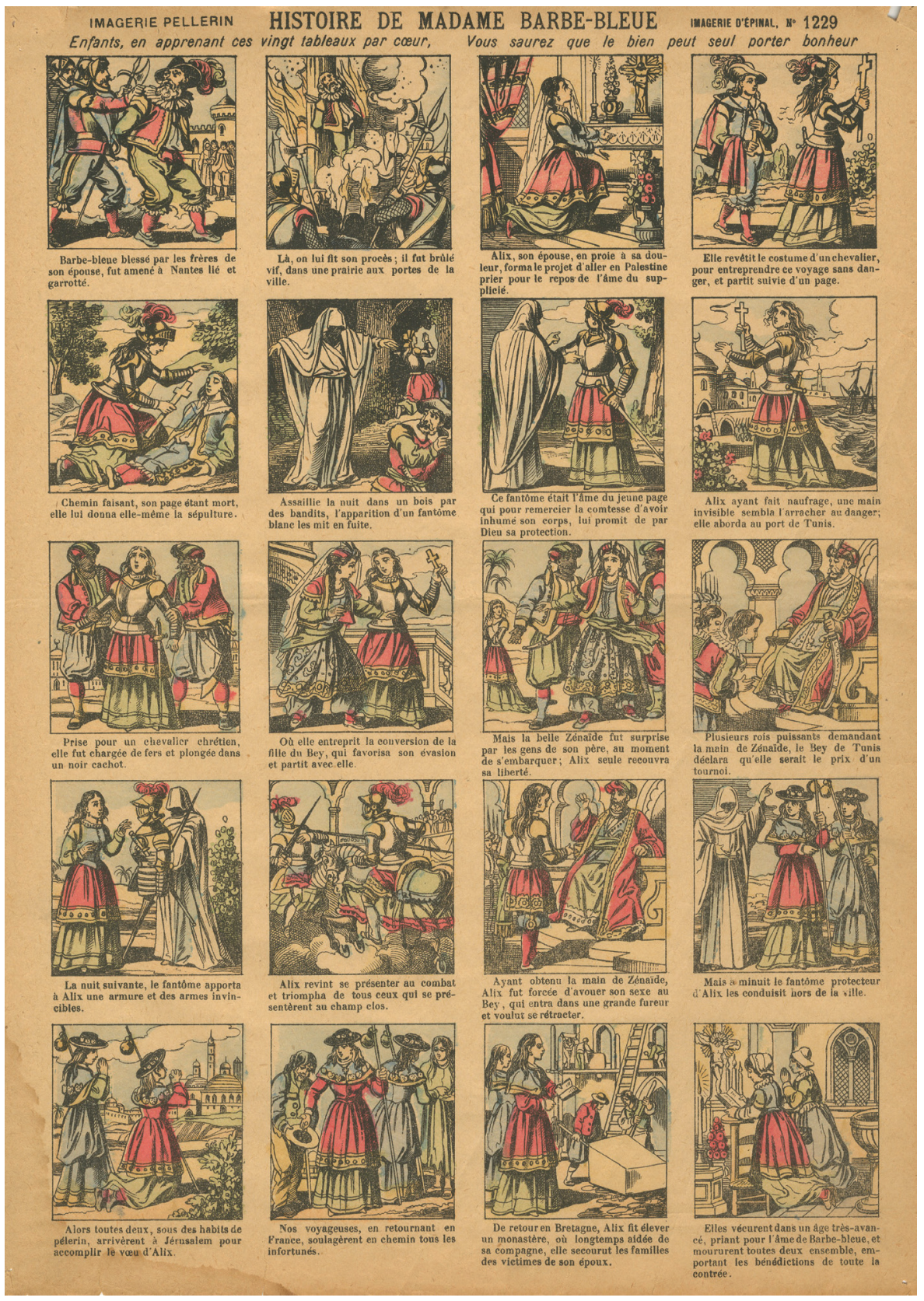

Fig. 5. - Planche ${ }^{\circ}$ 1229, Histoire de Madame Barbe-Bleue.

Collection privée. 
L'une des astuces imaginées par les auteurs de la Décadence pour donner suite aux contes consiste à tirer parti des liens de famille : sont alors racontées les histoires de la sœur du Petit Poucet ou des enfants de la Belle au bois dormant. Les imagiers en font tout autant. En I862, l'Imagerie Pellerin d'Épinal publie l'Histoire de Madame Barbe-Bleue (planche ${ }^{\circ}$ I229).

Veuve d'un Barbe-Bleue blessé par les frères de l'héroöne, puis jugé et condamné à être brûlé à Nantes, Madame Barbe-Bleue, prénommée Alix, s'en va en Palestine travestie en chevalier afin de prier pour le repos de l'âme de son époux. Le page qui l'accompagne trouve la mort en chemin et elle prend le temps de lui donner une sépulture. Dès lors, le fantôme du jeune page l'accompagne en permanence. Elle est faite prisonnière à Tunis à la suite d'un naufrage. Zénaïde, la fille du Bey, favorise son évasion et Alix en profite pour la convertir. Mais seule Alix parvient à s'enfuir car Zénaïde est reprise par les soldats de son père. Le Bey organise alors un tournoi et offre la main de sa fille au vainqueur qui n'est autre qu'Alix. Obligée d'avouer son sexe, Alix doit affronter la colère du Bey qui médite sa vengeance. Pendant la nuit, le fantôme du page permet à Alix et Zénaïde de s'enfuir. Elles vont à Jérusalem accomplir le vœu d'Alix puis reviennent en Bretagne, répandant des bienfaits sur leur passage. Une fois de retour, Alix crée un monastère où, aidée de sa compagne, elle secourt les familles des victimes de Barbe-Bleue. Elles bénéficient d'une longue vie consacrée à prier pour l'âme de Barbe-Bleue et meurent "toutes deux ensemble, emportant les bénédictions de toute la contrée ${ }^{20}$ ».

Cette planche d'images est une des plus passionnantes qu'il m'ait été donné d'analyser : elle est le produit d'un métissage narratif si dense, si riche, si complexe qu'elle doit être lue avant tout comme la preuve, s'il en était encore besoin, de l'intervention inventive des imagiers dans la chaîne de création et de transmission des contes. Comme tout conteur "populaire", l'imagier bricole les récits tout en sachant respecter la structure générique du conte. Existe-t-il une formule propre à Pellerin? Apparemment, il use d'une méthode créatrice qui exploite la translation, l'amalgame, la reprise, la dérive, le regroupement. Dans ce cas, l'Histoire de Madame Barbe-Bleue compose des variations sur un thème déjà donné. Mais ne va-t-il pas plus loin?

20. Pour mémoire, voici l'épilogue de la planche ${ }^{\circ}$ IIO2 de l'Imagerie Pellerin d'Épinal Histoire de la Barbe Bleue : "Barbe-Bleue étant mort, sa femme hérita de ses grands biens. Elle maria richement sa sœur Anne, acheta des charges de capitaines à ses frères et se remaria à un jeune seigneur qui la rendit heureuse.» 


\section{Gilles de Rais}

D'emblée, dès les deux premières vignettes, la planche de Pellerin renvoie à l'histoire de Gilles de Rais : "Barbe-bleue blessé par les frères de son épouse, fut amené à Nantes lié et garrotté. Là, on lui fit son procès; il fut brûlé vif, dans une prairie aux portes de la ville.» En I862, il n'est pas encore de bon ton de renvoyer dos à dos les deux personnages, comme les deux figures d'un même criminel : c'est plus tard, en I885, qu'Eugène Bossard publie une monographie devenue célèbre, consacrée au maréchal de France, Gilles de Rais, Maréchal de France dit Barbe-Bleue : "L'histoire nous présente Gilles de Rais tel qu'il fut devant ses juges; la tradition tel qu'il apparaît aux yeux du peuple ${ }^{21}$.» Mais en réalité, l'artisan de la mise en concurrence du mythe historique et du conte, c'est Michelet. En I862, précisément, il publie La Sorcière:

Ces contes ont une partie historique, rappellent les grandes famines (dans les ogres, etc.). Mais généralement ils planent bien plus haut que toute l'histoire, sur l'aile de l'Oiseau bleu, dans une éternelle poésie, disent nos vœux, toujours les mêmes, l'immuable histoire du cœur. Le désir du pauvre serf de respirer, de reposer, de trouver un trésor qui finira ses misères, y revient souvent. [...] Une tendresse infinie est dans tout cela. Cette âme enchantée ne pense pas à elle seule. Elle étend sa compassion sur la dame même du château, la plaint d'être dans les mains de ce féroce baron (BarbeBleue) ${ }^{22}$.

Il évoque donc le conte comme l'aspiration touchante d'un peuple en souffrance. Les larmes du monstre qui reconnaît sa laideur appellent une "tendresse infinie» et la femme du serf prend en pitié la dernière épouse du redoutable Barbe-Bleue, au croisement du cœur et de l'histoire. Après avoir brièvement évoqué les barbaries perpétrées complaisamment par l'Église, Michelet poursuit :

Que devaient être les seigneurs laïques? Quel était l'intérieur de ces noirs donjons que d'en bas on regardait avec tant d'effroi? Deux contes, qui sont sans nul doute des histoires, La Barbe Bleue et Grisélidis, nous en disent quelque chose. Qu'était-il pour ses vassaux, ses serfs, l'amateur de tortures qui traitait ainsi sa famille? Nous le savons par le seul à qui l'on ait fait un procès, et si tard! Au quinzième siècle : Gilles de Retz, l'enleveur d'enfants ${ }^{23}$.

2I. E. Bossard, Gilles de Rais, Maréchal de France dit Barbe-Bleue, Paris, H. Champion, I885, rééd. Grenoble, Jérôme Millon, 1992, p. 322.

22. J. Michelet, La Sorcière, Paris, I862, rééd. Paris, Garnier-Flammarion, 1966, p. 64.

23. Ibid., p. 70. 
Michelet lance ainsi Gilles de Rais dans une bataille littéraire qui s'achève en 1909 avec les Sept Femmes de la Barbe Bleue d'Anatole France : là où Michelet présentait des doutes, le romancier avance des certitudes. France replace l'Histoire, le mythe et le conte dans un même souffle, une même inspiration. Il réconcilie le romanesque et l'historique, et la notoriété du méchant seigneur de Rais rencontre une audience toujours plus grande. Face à la nouvelle gloire du maréchal, devant les charniers d'enfants que l'imagination compte désormais par dizaines, que sont quelques malheureuses égorgées?

Faut-il en déduire qu’à Épinal, Pellerin est sensible au texte de Michelet, qu'il anticipe cette vague littéraire parisienne qui fera de Barbe-Bleue le concurrent malheureux de Gilles de Rais — et vice versa? Rien n'est moins sûr. Car Pellerin dispose d'une source beaucoup plus abordable : son confrère parisien Charles-Eugène Glémarec a imprimé en 1858, soit quatre ans avant la publication de La Sorcière, une planche d'images L'Histoire de la Barbe Bleue (conte des fées) qui comporte un paragraphe explicatif, fait rarissime dans l'imagerie :

Le fonds de ce conte est historique. Voici les documents qui servirent à Perrault pour composer cette fiction. [...] En plusieurs occasions, Gilles de Retz avait donné des manifestations de bravoure, mais il avait déplu à Philippe, Duc de Bourgogne, qui était tout-puissant. L'évêque de Nantes, voulant faire sa cour à Philippe, cita à son tribunal le Maréchal de Retz. Des témoins déposèrent qu’il avait à son service des enchanteurs pour trouver des trésors et que, pour ses enchantements, il employait le sang des jeunes filles qu'il faisait égorger. On le condamna à être brûlé vif. Son bûcher fut dressé dans une prairie, nommée prairie de Mauves, près de la ville ${ }^{24}$.

Libraire-éditeur, graveur, lithographe et fabricant d'images, «éditeur et marchand d'estampes» selon les documents qu'il signe, Glémarec a exercé à Paris de 1845 à I860. Installé rue de la Harpe, puis quai du Marché-Neuf, enfin quai des Augustins et rue Saint-Jacques où il réunit librairie et atelier, il est reconnu comme le plus grand imagier parisien de son temps. Son entreprise est florissante dès I845 puisqu'il réussit à racheter les bois de Pierre-François Godard d'Alençon, graveur sur bois dont la notoriété dépasse la Normandie et qui s'est fait une spécialité des Fables d'Ésope et de La Fontaine. Le talent artistique et l'opportunisme financier et politique de Glémarec lui permettent de constituer un fonds de gravures aussi riche qu'éclectique : des planches de contes et de fables, des féeries telles que ce Barbe-bleue, ou la Fée Perruchette avec «changements à vue, des métamorphoses, des apparitions fantastiques, des danses, décors et cos-

24. Cité par A. Renonciat, art. cité, p. II7. Planche nº 146. 
tumes nouveaux", des almanachs, des calendriers bonapartistes, des caricatures révolutionnaires en I848, ou encore le Véritable Portrait du Juif Errant. À ce stade de l'enquête, une question reste en suspens : à quelle source a-t-il donc puisé l'argument historique qui associe Barbe-Bleue à Gilles de Rais?

\section{«Petite Histoire Nantaise À Cinq Centimes»}

C'est en I84I qu'est imprimée à Nantes par Camille Mellinet La Véritable Histoire du Barbe-Bleue Nantais ou du Maréchal de Retz ${ }^{25}$. Ce petit livret de huit pages fait partie de la collection «Petite Histoire Nantaise À Cinq Centimes» et il est conseillé de "conserver ces petits cahiers, dont la publication va continuer, chacun pourra en former plus tard un ou plusieurs volumes». C'est à ma connaissance la toute première occurrence d'une association écrite du personnage de Barbe-Bleue avec celui de Gilles de Rais. "Ce n'est point un conte fait à plaisir : c'est de l'histoire écrite par un greffier du Xve siècle», nous dit l'introduction. "Ce personnage effrayant [...] a acquis une immense célébrité sous le nom de Barbe-Bleue. - Oui, ce terrible Barbe-Bleue, dont la vie a été arrangée en un conte pour les enfants, a véritablement existé, et c'est dans la ville de Nantes qu'il a reçu la punition de ses forfaits ${ }^{26}$.» S'il est question de la bravoure de Gilles pendant la Guerre de Cent Ans, de son dévouement à Jeanne d'Arc, l'auteur insiste aussi sur sa fortune, la magnificence de ses banquets et, bien entendu, sur la disparition des enfants égorgés — surtout des jeunes filles. L'amalgame des deux histoires s'opère avec talent, associant les motifs de l'une à ceux de l'autre, tel que cette «belle barbe, toujours arrangée avec soin, qui avait une sorte de reflet bleuâtre, soit naturel, soit par l'effet des essences qu'il employait». L'épilogue est particulièrement intéressant :

Le $26^{e}$ jour du mois d'octobre, au milieu d'une procession générale, Gilles de Retz fut conduit au supplice sur la prée de la Magdelaine, avec ses complices, au nombre de deux, et les trois têtes tombèrent en juste expiation de tant de crimes. Le corps de Gilles de Retz fut conduit à l'église des Carmes.

Pas de bûcher donc, mais une décapitation. Et ces quelques lignes conclusives viennent à la suite :

25. Petite Histoire Nantaise À Cinq Centimes. La Véritable Histoire du Barbe-Bleue Nantais ou du Maréchal de Retz, Nantes, Imprimerie de C. Mellinet, I84I.

26. Ibid., p. I. 
Suivant l'usage du temps [dit un historien], les pères et mères de famille qui avaient entendu sa confession, jeûnèrent trois jours pour lui mériter la miséricorde divine, et infligèrent à leurs enfants la peine du fouet, afin qu'ils gardassent dans leur mémoire le souvenir de ce châtiment terrible. Une croix de pierre fut élevée sur l'emplacement du bûcher où avait péri Gilles de Retz. Une chapelle la remplaça, et on en voit encore des vestiges à l'entrée de la chaussée de l'Hôpital, près le portail de l'Hôtel-Dieu de ce côté, où s'apercevait naguères une niche dans laquelle se trouvait la Sainte-Vierge entre Saint-Gilles et Saint-Laud. Cette image a été longtemps connue sous le nom de la Bonne Vierge de Créelait. — C'est le dernier souvenir du Barbe-Bleue nantais ${ }^{27}$.

Entre la décapitation et le bûcher, sur lequel périrent effectivement brûlés Gilles de Rais et ses deux valets, l'auteur hésite : les dernières deux pièces du puzzle, jusque-là infaillible, ne s'emboîtent pas. Plus de vingt ans plus tard, à Épinal, Pellerin fait son choix, étrangement renversé : ce sera le bûcher mais celui qui y meurt est Barbe-Bleue. Et c'est Madame Barbe-Bleue, Alix, qui incarne à elle seule les "pères et les mères de famille " et qui, repentante en lieu et place de la Bretagne, bâtisseuse d'un refuge monacal, reprend à son compte les dévotions du pays nantais à la mémoire de Gilles de Rais.

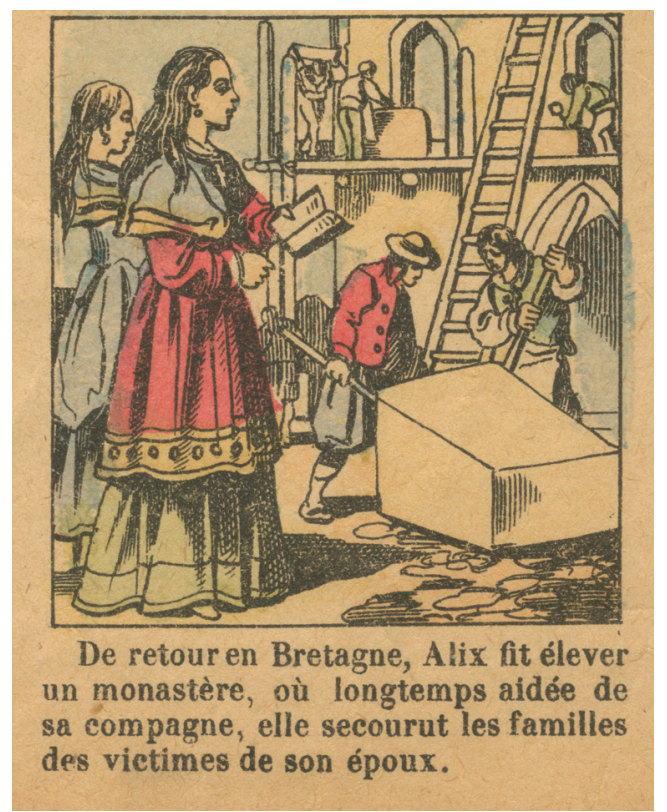

Fig. 6. - Vignette extraite de la planche $\mathbf{n}^{0}$ I229 tirée de l'Histoire de Madame Barbe-Bleue.

Collection privée.

27. Ibid., p. 8. 


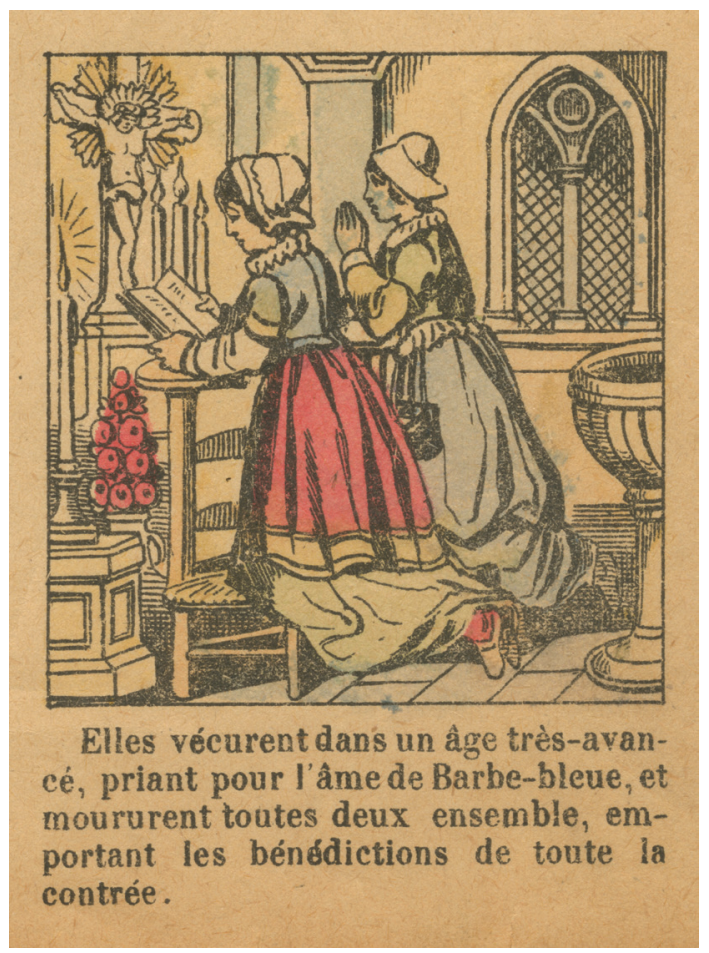

Fig. 7. Vignette extraite de la planche $\mathbf{n}^{\circ}$ I229 tirée de l'Histoire de Madame Barbe-Bleue.

Collection privée.

Quelques mots sur Camille Mellinet, l'imprimeur nantais de La Véritable Histoire du Barbe-Bleue Nantais : imprimeur, journaliste, historien, engagé dans les milieux républicains malgré sa passion pour la Chouannerie, il prend la tête en I820 de la maison d'édition fondatrice du premier journal d'opinion nantais. Il développe l'entreprise au point où il peut fonder plusieurs revues littéraires et scientifiques. C'est lui qui donne à l'ethnologue breton Émile Souvestre son premier emploi à Nantes et qui lui permet de s'impliquer dans la vie culturelle de la ville. Il publie deux de ses recueils poétiques et participe à ses toutes premières collectes de contes. Proches l'un et l'autre du saint-simonisme, ce qui conduira Souvestre à soutenir la Révolution de I848, ils tentent d'associer leur engagement pour une utopie sociale et leur attachement à une autonomie régionaliste. Décédé en I843, Camille Mellinet laisse une partie de son fonds à Pierre-François Godard d'Alençon qui a travaillé dans sa maison d'édition nantaise à ses 
débuts. L'on peut supposer que les livrets de la Petite Histoire Nantaise $\grave{A}$ Cinq Centimes s'y trouvaient. L'enquête éditoriale finit donc ici : Pellerin se fait donc l'héritier de ces imprimeurs, de Mellinet de Nantes à Godard d'Alençon, de Godard d'Alençon à Glémarec de Paris. Son œuvre excède largement les habituelles pratiques d'intervention sur le thème de référence, que les historiens de l'illustration ont identifiées en terme de détournement, de subversion, de manipulation, d'exploitation, de trahison, etc. Sa créativité va aussi bien au-delà des notions de suite, de fantaisie, de variation, que l'on situe dans les registres sémantiques du relais, du jeu ou de la composition musicale. Car Pellerin ne se contente pas de broder sur un thème, broderies qui seraient inscrites dans le processus même de l'œuvre. L'on a pu dire jusque-là qu'à partir d'un texte-matrice destitué de son statut littéraire, les imagiers intervenaient sur le conte pour suggérer leur fantaisie inventive et porter l'accent sur leurs stratégies de diversification des images. Pellerin fait beaucoup plus que cela : tout d'abord, son histoire est si chrétienne, si édifiante et si ostensiblement moralisatrice qu'elle devient un texte de propagande conservatrice - et ce faisant il prend le contre-pied de ses devanciers breton, normand et parisien. Ensuite, Pellerin transcrit un autre conte.

\section{Alis de Bourges}

En effet, l'Histoire de Madame Barbe-Bleue existe depuis longtemps, en un temps où l'héroïne s'appelait Alis et non Alix ${ }^{28}$. Elle était l'épouse d'Herpin de Bourges, baron de Charlemagne. Bannie avec son mari de la cour, elle est enlevée par des brigands; elle leur échappe et se travestit en homme, embarque pour la Terre Sainte, dans l'espoir d'y retrouver Herpin. Sur le chemin et après bien des rebondissements, elle est engagée comme aidecuisinier de l'émir de Castille. Elle prend le nom de Ballian d'Aragonne, apprend l'arabe et travaille pendant dix-huit ans dans les cuisines de l'émir de Tolède. La ville est assiégée par un géant qui se vante de pouvoir affronter

28. Il est probable que l'origine du prénom Alix soit aussi historique : la seconde fiancée de Gilles de Rais, Béatrix de Rohan, fille aînée d'Alain de Porhoët et nièce du duc de Bretagne, décède peu de temps après la signature du contrat en novembre I4I8, à l'instar de la première fiancée, Jeanne Paynel, décédée elle aussi quelques mois après avoir été fiancée au Maréchal de France en janvier I417. Peut-être y a-t-il eu un glissement sémantique de Béatrix à Alix. En 1909, dans Les Sept Femmes de la Barbe bleue et autres contes merveilleux, Anatole France prénomme la sixième épouse Alix. 
six hommes ensemble. Personne n'ose relever le défi sauf Ballian-Alis qui a appris, en rêve, que Jésus l'a choisie pour abattre le géant. Elle s'acquitte de sa mission. Florie, la fille de l'émir de Tolède, tombe amoureuse du vaillant Ballian. Tout d'abord embarrassée puis séduite, Alis ne cède pas à la tentation; elle lui avoue son identité et s'enfuit. Florie est accusée par son père de l'avoir tuée mais des magiciens parviennent à convaincre l'émir de l'innocence de sa fille. Au final, mari et femme sont réunis.

Cette histoire est l'introduction de la chanson de geste Lion de Bourges, composée aux alentours de 1350 , en langue picarde ${ }^{29}$. Le thème de la femme travestie en homme est un des types folkloriques les plus répandus et les plus prolifiques que l'on puisse rencontrer ${ }^{30}$. Au Moyen Âge, les personnages d'Yde, Silence, Grisandole, Blanchandine sont les plus connus de cette production. Le costume est alors un élément de reconnaissance important. On exige des vêtements et des accessoires qui les accompagnent de signaler le sexe et la condition de l'être qui les arbore. C'est pourquoi, dans les œuvres poétiques, quand une femme emprunte des vêtements masculins pour dissimuler son identité et pouvoir voyager à son aise, elle brave un fort interdit social. Les travesties choisissent de prendre des habits d'homme, ou plus précisément d'emprunter l'apparence et l'équipement d'un chevalier, pour fuir ou pour rechercher leur mari - comme c'est le cas d'Alis ou encore de la Josiane de Beuve de Hantone. Dans cette production épique, exprimer le désir de remplir, en armure de chevalier, un rôle de défense efficace pour protéger une citadelle ou bien l'honneur d'une jeune fille, est une volonté légitime qui a vite passé pour naturelle et féminine. Au fur et à mesure que le moule des "récits d'enfance» s'est communiqué de la sphère des petits chevaliers à celle des petites héroïnes, la logique de contamination progressive a entraîné une programmation de la structure narrative qui prévoit pour une fille en fuite un déguisement, des exploits guerriers et un beau mariage : sur ce schéma de base les épi-

29. Lion de Bourges (Ms BNF fr. 22555), W. W. Kibler, J.-L. Picherit et Th. Fenster (éds), Genève, Droz, 1980. Je remercie J.-P. Martin (université d'Artois, Arras) de m’avoir indiqué ce texte.

30. C. Velay-Vallantin, La fille en garçon, Carcassonne, Garae/Hésiode, I992.

Le conte de la femme travestie en homme est identifié par A. Aarne et S. Thompson, The Types of the Folktale, F. F. Communications, Helsinki, 1960, par le conte-type $884 \mathrm{~A}:$ A Girl Disguised as a Man is Wooed by the Queen, le conte-type 884 B : The Girl as Soldier (voir aussi le conte-type 514), le conte-type 884 B : Girl Dressed as Man Deceives the King. Voir, dans P. Delarue et M.-L. Tenèze avec la collaboration de J. Bru, Le Conte populaire français : Contes-nouvelles, Paris, Éditions du Comité des travaux historiques et scientifiques, 2000, le conte-type 884, La fille en garçon au service du roi, p. 74-77. 
sodes n'ont plus qu'à devenir plus ou moins développés ${ }^{31}$. Qu'il s'agisse de Lion de Bourges ou de bien d'autres chansons de geste mettant en scène des femmes travesties, toutes les «meschinations» sont bonnes pour créer des situations ambiguës, où l'homosexualité est toujours suggérée ${ }^{32}$. La carte d'un Tendre équivoque est d'autant plus jouée que les héroïnes, entre deux séances de déshabillage, de troubles frôlements et d'attachements lesbiens, sont vertueuses, dispensatrices de bienfaits charitables et propagandistes d'une foi inébranlable.

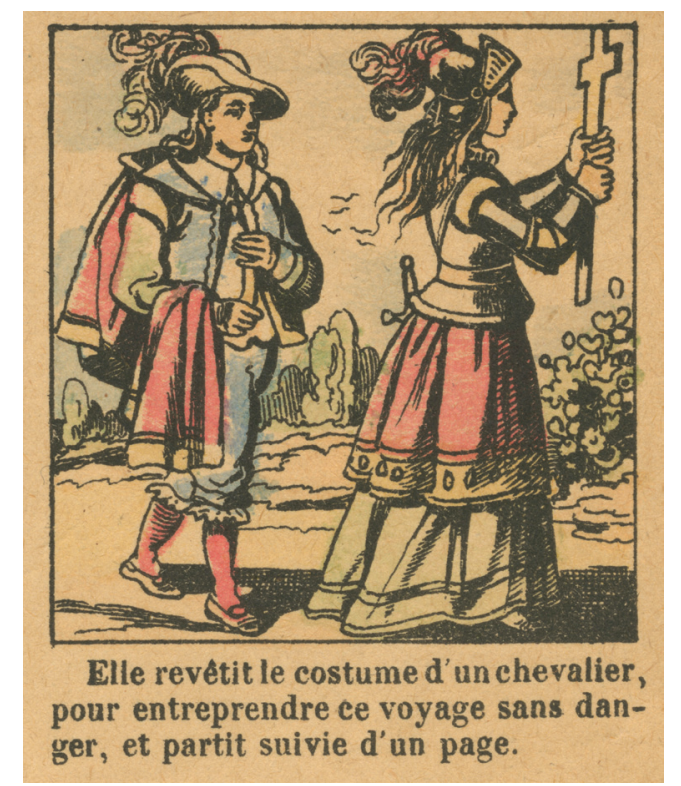

Fig. 8. - Vignette extraite de la planche $\mathrm{n}^{\circ} \mathrm{I} 229$ tirée de l'Histoire de Madame Barbe-Bleue.

Collection privée.

31. C. Cazanave, D'Esclarmonde à Croissant. Huon de Bordeaux, l'épique médiéval et l'esprit de suite, Besançon, Presses universitaires de Franche-Comté, 2007, p. I3I-I62 et en particulier p. I44-I45.

32. M. Perret, «Travesties et transsexuelles: Yde, Silence, Grisandole, Blanchandine», Romance Notes, vol. $25, \mathrm{n}^{\circ} 3$, 1985, p. 328-340. 


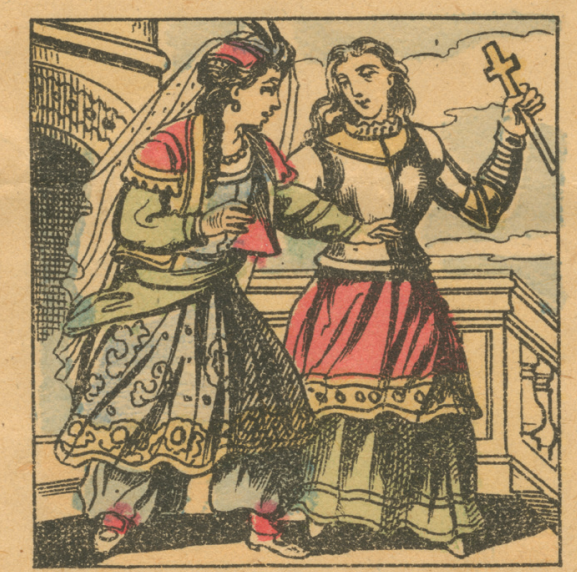

Où elle entreprit la conversion de la fille du Bey, qui favorisa son évasion et partit avec elle.

Fig. 9. - Vignette extraite de la planche $\mathbf{n}^{\circ}$ I229 tirée de l'Histoire de Madame Barbe-Bleue.

Collection privée.

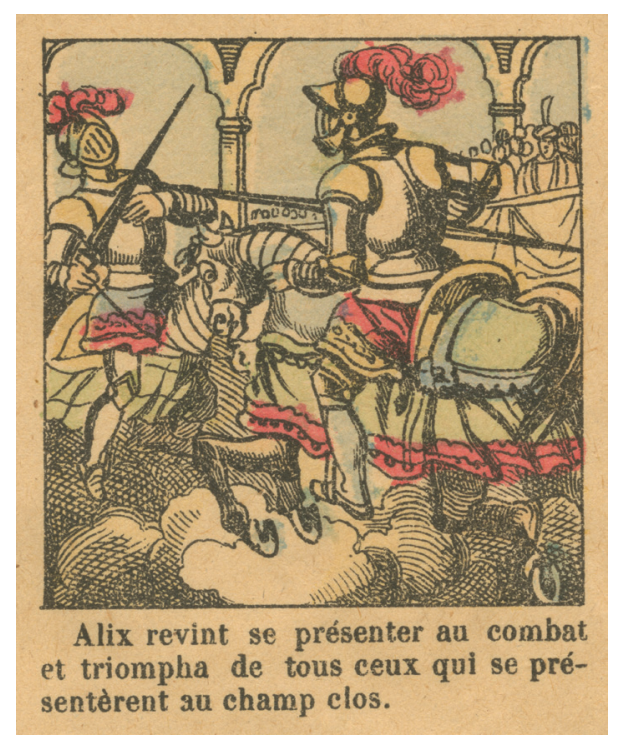

Fig. Io. - Vignette extraite de la planche ${ }^{0}$ I229 tirée de l'Histoire de Madame Barbe-Bleue.

Collection privée. 
De tous les récits chargés de ce thème florissant, Lion de Bourges est sans conteste celui dont la structure narrative se rapproche le plus de la planche de Pellerin. Quant au couple d'Alix et de Zénaïde, il reproduit à l'évidence celui d'Alis et de Florie. Long et savant, composé en alexandrins et en octosyllabes, ce texte de langue picarde pouvait-il être connu de l'imagier? Aurait-il consulté une édition résumée en français? Une version orale lui serait-elle parvenue? Le maillon manquant ne nous est pas connu mais il a existé, sans nul doute. Cette hypothèse est validée par une production plus tardive d'un auteur de la Décadence. En I9I2, Gabriel Salvat publie La Barbe Bleue: Gisèle, la nouvelle épouse de Barbe-Bleue, prend le nom d'Alain et se travestit en ménestrel pour entreprendre le voyage qui la mènera au château où elle espère convertir le monstre en toute sécurité. Mais c'était sans compter avec l'attraction qu'il éprouve pour les jeunes garçons :

Alors la Barbe-Bleue la saisit par les poignets et l'attira à lui. Il approcha du sien son visage stupéfait. Ses regards pâles descendirent lentement dans la profondeur de ses yeux. Et il se parlait à lui-même en évoquant des souvenirs : - Ces yeux, murmurait-il, ont des regards de femme... de la grâce, de la douceur... Des clartés familières, éteintes depuis longtemps, s'y rallument et brillent, puis s'éteignent à nouveau pour renaître encore... Pas encore mortes, pas encore oubliées... éternellement présentes... Alain, qui donc es-tu ${ }^{33}$ ?

Initiés par l'ambivalence sexuelle de son épouse, les tourments fantastiques de Gilles de Rais ressurgissent : ils murmurent à l'oreille de BarbeBleue. Depuis qu'un imprimeur nantais les a mis en composition, ils n'ont jamais cessé d'être.

\section{Conclusion}

En 1987 , je tentais de comprendre les formes de liberté prises par les imagiers à l'égard des contes de référence non comme un avatar littéraire, mais comme un mode spécifique d'appropriation d'un texte hybride, tout à la fois œuvre d'écrivain et classique du folklore et de l'oralité. Il s'agissait pour moi d'analyser comment cet artisanat de l'image qui connaissait alors, au XIX ${ }^{\mathrm{e}}$ siècle, un si profond renouvellement de ses publics et de ses fonctions traditionnelles, pouvait opérer une récupération de son patri-

33. G. Salvat, La Barbe-Bleue, Paris, Bernard Grasset, I912, p. 67.

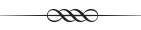


moine propre, exporté par Perrault dans le monde lettré34. L'étude des deux cas que je viens d'effectuer me permet de redire qu'il existe, dans un même mouvement, une spécificité des pratiques créatives des imagiers, et une autorité et une autonomie des images dans les processus de transmission du patrimoine culturel traditionnel. Mais la question que je pose aujourd'hui est autre : peut-on encore parler d'appropriation? L'imagier a-t-il vraiment cherché à récupérer un patrimoine qu'il aurait identifié et reconnu comme initialement sien? Cela occulte trop facilement cette part complexe de création qui s'élabore «entre contraintes transgressées et libertés bridées ${ }^{35}$ ». Contre une analyse qui suppose l'asservissement de l'imagier et de son public aux messages inculqués, il faut rappeler que la réception est création, et la consommation production. Mais aussi, contre la perspective inverse qui postule l'absolue liberté des individus et la force des imaginations sans limites, il faut rappeler que toute création est enserrée dans des conditions de possibilité historiquement variables et socialement inégales. Au cœur de ce croisement paradoxal, un écheveau de contes sans fin déroule ses fils bigarrés, tous marqués par le sceau de la singularité, de l'écart et de l'anomalie.

34. C. Velay-Vallantin, "Le miroir des contes. Perrault dans les Bibliothèques bleues", dans R. Chartier (dir.), Les Usages de l'imprimé, Paris, Fayard, I987, p. I42.

35. R. Chartier, «Histoire, littérature et pratiques. Entre contraintes transgressées et libertés bridées", Le Débat, n ${ }^{\circ}$ I03, janvier-février 1999, p. 162. 